\title{
The effect of wave-induced turbulence on the ocean mixed layer during tropical cyclones: Field observations on the Australian North-West Shelf
}

\author{
A. Toffoli, ${ }^{1}$ J. McConochie, ${ }^{2}$ M. Ghantous, ${ }^{1}$ L. Loffredo, ${ }^{3}$ and A. V. Babanin ${ }^{1}$ \\ Received 25 November 2011; revised 30 May 2012; accepted 31 May 2012; published 20 July 2012.
}

[1] Field observations of water temperature on the Australian North-West Shelf (Eastern Indian Ocean) with the support of numerical simulations are used to demonstrate that the injection of turbulence generated by the wave orbital motion substantially contributes to the mixing of the upper ocean. Measurements also show that a considerable deepening of the mixed layer occurs during tropical cyclones, when the production of wave-induced turbulent kinetic energy overcomes the contribution of the current-generated shear turbulence. Despite a significant contribution to the deepening of the mixed layer, the effect of a background current and atmospheric forcing are not on their own capable of justifying the observed deepening of the mixed layer through most of the water column. Furthermore, variations of a normally shallow mixed layer depth are observed within a relatively short timescale of approximately 10 hours after the intensification of wave activity and vanish soon after the decay of storm surface waves. This rapid development tends also to exclude any significant contribution by wave breaking, as small rates of vertical diffusivity for wave breaking-induced turbulence would require longer timescales to influence the depth of the mixed layer.

Citation: Toffoli, A., J. McConochie, M. Ghantous, L. Loffredo, and A. V. Babanin (2012), The effect of wave-induced turbulence on the ocean mixed layer during tropical cyclones: Field observations on the Australian North-West Shelf,

J. Geophys. Res., 117, C00J24, doi:10.1029/2011JC007780.

\section{Introduction}

[2] The mixing of the upper ocean produces a subsurface layer of uniform density that directly affects the air-sea exchange of heat, momentum and gases. Its depth (hereafter referred to as mixed layer depth, $M_{l d}$ ) ranges from 20 to $200 \mathrm{~m}$ and can be affected by many sources. For example, the shear generated by wind-driven currents, which leads to Kelvin-Helmholtz instabilities, is generally responsible for the mixing over a considerable vertical depth [e.g., Mellor and Durbin, 1975]. Moreover, the interaction between wind-driven shear currents and surface waves produces Langmuir circulations that significantly contribute to the mixing of the near-surface stratification [Li et al., 1995; Li and Garrett, 1997; Kukulka et al., 2010; Sullivan and McWilliams, 2010]. Wind-generated waves also dissipate their energy and eventually transfer their momentum to the ocean in the form of current and turbulence, contributing to the exchange of heat and gasses at the air-sea interface [e.g.,

\footnotetext{
${ }^{1}$ Centre for Ocean Engineering Science and Technology, Swinburne University of Technology, Hawthorn, Australia.

${ }^{2}$ Woodside Energy Ltd., Perth, Australia.

${ }^{3}$ Katholieke Universiteit Leuven, Heverlee, Belgium.

Corresponding author: A. Toffoli, Centre for Ocean Engineering Science and Technology, Swinburne University of Technology, PO Box 218, Hawthorn, Vic 3122, Australia. (toffoli.alessandro@gmail.com)

(C)2012. American Geophysical Union. All Rights Reserved. 0148-0227/12/2011JC007780
}

Craig and Banner, 1994; Babanin, 2011]. Commonly, the turbulence injected by breaking waves is perceived as one of the main means to transfer wind momentum into subsurface waters and has been implemented in turbulence closure schemes of ocean circulation and ocean mixing models [see, e.g., Chalikov and Belevich, 1993; Baumert et al., 2005; Huang et al., 2011]. However, direct injection of turbulence from wave breaking extends until a depth comparable with the significant wave height [see Terray et al., 1996]. Moreover, the vertical turbulent diffusion rates are generally small (between $10^{-2} \mathrm{~m}^{2} / \mathrm{s}$ near the surface and $10^{-4} \mathrm{~m}^{2} / \mathrm{s}$ at middepth [Huang et al., 2011]) and hence turbulence may take approximately 30 days to diffuse through a water column of $50 \mathrm{~m}$. Considering that the lifetime of turbulence is generally short and of the order of the turn-around time of the vortex [see, e.g., Babanin et al., 2009], turbulence is expected to be dissipated well before reaching deeper layers. Therefore, the contribution of breaking-induced turbulence decays rapidly with distance from the surface and, as a consequence, the contribution of wave breaking to the overall ocean mixing can be regarded as minimal [Rapp and Melville, 1990; Huang et al., 2011].

[3] Even without the occurrence of breaking, turbulence can be forced into the ocean by wave motion. This has been highlighted in a number of experimental [Yefimov and Khristoforov, 1971; Cavaleri and Zecchetto, 1987; Gemmrich and Farmer, 2004], theoretical [Thais and Magnaudet, 1996; Phillips, 2001] and numerical [Qiao et al., 2004; Pleskachevsky et al., 2005] studies during the 
past decades. However, only recently has the concept of the turbulence generated by non-breaking waves been confirmed [Babanin, 2006; Babanin and Haus, 2009; Dai et al., 2010]. Experimental evidence has substantiated a transition from laminar to turbulent wave-induced orbital motion, inducing the velocity spectra to exhibit the Kolmogorov interval associated with the presence of isotropic turbulence. Despite an intermittent nature, this transition has been estimated empirically to occur when a wave-amplitude-based Reynolds number

$$
R e=\frac{\omega\left[a_{0} \exp (-k z)\right]^{2}}{\nu}
$$

where $a_{0}$ is the wave amplitude at the water surface, $z$ is the water depth, $k$ is the wave number, $\omega=\sqrt{g k}$ is the angular frequency and $\nu$ is the kinematic viscosity of the ocean water, becomes greater than a threshold value $R e_{c r}$. Based on field observations and laboratory experiments with monochromatic waves, $R e_{c r}$ was estimated to vary between 2600 and 3500 [see Babanin, 2006].

[4] Unlike wave breaking, which is a surface phenomenon, wave motion injects turbulence directly into the subsurface layers and provides an immediate supplementary turbulent source for ocean mixing [see Dai et al., 2010; Huang et al., 2011; Pleskachevsky et al., 2011]. The depth of the ocean layer subjected to wave-induced motion (hereafter referred to as wave-induced mixed layer depth) can be derived from (1) by calculating the water depth at which the Reynolds number assumes the critical value $R e_{c r}$ [Babanin, 2006]:

$$
z_{c r}=\frac{g}{2 \omega^{2}} \log \left(\frac{a_{0}^{2} \omega}{R e_{c r} \nu}\right)
$$

where $g$ is the acceleration due to gravity. For oceanic random wavefields, the surface wave amplitude can be approximated by half the significant wave height, $H_{s}$, and the wave frequency can be represented by the spectral peak frequency, $\omega_{p}$; for convenience, an average value of 3050 is used for $R e_{c r}$. Note that the wave-induced mixed layer extends to depths comparable to half the wavelength (e.g., this corresponds to approximately $100 \mathrm{~m}$ for a wave period of $12 \mathrm{~s}$ in deep water conditions), which is much deeper than the subsurface layer affected by Langmuir circulations [see, e.g., Li et al., 1995; Babanin et al., 2009]. However, it is also important to mention that $z_{c r}$ is a limit which would only be reached if the wave forcing took place for a sufficiently long time.

[5] The wave-induced mixed layer depth (2) responds to variations of the sea state by expanding or contracting [see Babanin, 2006]. During summer periods, when natural convection is ineffective, the mixed layer depth (and its variability) may be strongly affected by the injection of wave-induced turbulence, especially during cyclone seasons. Pioneering investigations on the effect of turbulence induced by wave orbital motion in climate modeling, in this respect, have demonstrated that the adoption of a variable mixed layer depth based on $z_{c r}$ instead of a constant monthly value for summer periods can result in a significant improvement for the prediction of the surface water temperature, upper-ocean thermal structure and total mixed layer depth compared to traditional mixing schemes [Qiao et al., 2004, 2008; Babanin et al., 2009]. Note, however, that the direct injection of turbulence into the subsurface layers might not necessarily produce an instantaneous variation of the actual mixed layer depth (i.e., depth of uniform temperature and/or salinity), which on the contrary might require some time to adjust to the turbulent field.

[6] In this paper, oceanographic data including wave spectral parameters, water temperature and current velocity fields are used to discuss the capability of waves to modify the depth of the mixed layer. Data have been gathered in the Eastern Indian Ocean (tropics) over the Australian NorthWest Shelf during the Austral summer. According to climate data by the U.S. Naval Research Laboratory (http://www7320. nrlssc.navy.mil/nmld/nmld.html), the mixed layer depth ranges, on average, between 20 and $40 \mathrm{~m}$. The investigation discussed in the following sections tends to confirm that the rapid intensification of wave activity in tropical cyclones forces the production of wave-induced turbulence into a subsurface layer twice as deep as the average mixed layer depth. Particularly, the mixed layer depth is observed to be consistent with predictions based on wave-induced turbulence, when the production of turbulence kinetic energy associated with wave motion overpowers the contribution of shear current. In this respect, simulations based on an ocean turbulence model indicate that the effect of background currents alone is not able to induce the significant deepening of the mixed layer depth that was observed at the peak of tropical cyclones.

\section{Field Measurements}

[7] Field measurements are used to trace the temporal evolution of the mixed layer depth. The measurement station is at the North Rankin A Gas Platform, which is located on the Australian North-West Shelf approximately $135 \mathrm{~km}$ offshore (Figure 1). The seafloor is gently sloping with a water depth of $125 \mathrm{~m}$ at the measurement site. The region is characterized by a background current, the Leeuwin Current, with an average speed of about $0.1-0.15 \mathrm{~m} / \mathrm{s}$ with peaks during the Austral winter [see, e.g., Domingues, 2006]. The area is also subjected to a semi-diurnal tide, which generates largeamplitude internal waves in combination with a rather steep bathymetry at the edge of the continental shelf and a yearround stratification due to the effect of a strong solar heating (these waves are commonly known as internal tides [Holloway, 1994; Van Gastel et al., 2009]). Note that the internal wavefield is of depression during summer and elevation during winter.

[8] Oceanographic data have been collected by Woodsite Energy Ltd. during tropical cyclones for the last three decades [see, e.g., Holloway, 1994; Young, 2006; Van Gastel et al., 2009; Toffoli et al., 2010]. Without loss of generality, we limit the present investigation to measurements recorded between January and April, 2006. An array of five acoustic current meters and temperature sensors was suspended on a taut wire extending from the base of the North Rankin A Platform's flare tower to the seabed to monitor current speed, current direction and water temperature. Instruments were deployed at depths of $7.5 \mathrm{~m}, 22.5 \mathrm{~m}, 50.0 \mathrm{~m}, 75.0 \mathrm{~m}$ and $95.0 \mathrm{~m}$ and operated at a sampling interval of 60 seconds. The sensor closest to the surface did not operate continuously over the entire period and hence was excluded from analysis. 


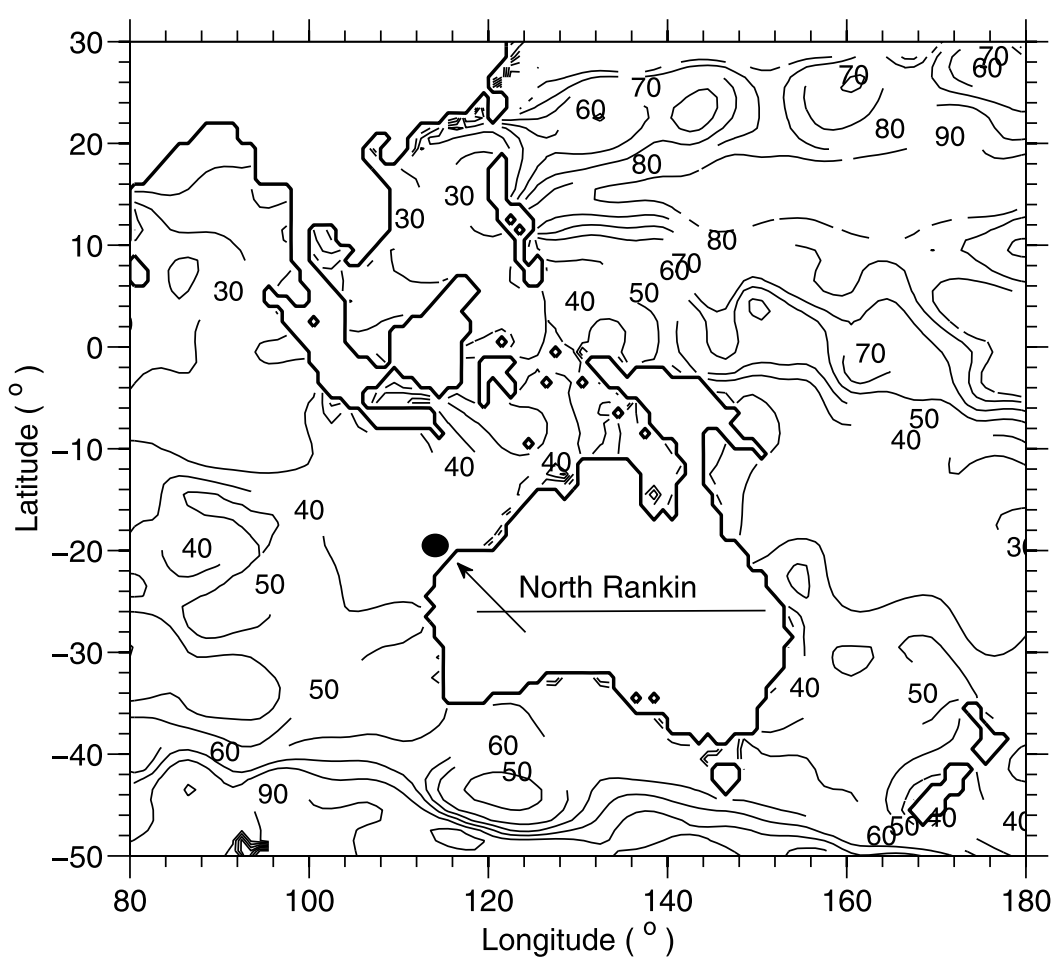

Figure 1. Location of the North Rankin A Gas Platform. Contour lines indicate the mixed layer depth (source: U.S. Naval Research Laboratory, http://www7320.nrlssc.navy.mil/nmld/nmld.html).

Note also that a number of atmospheric data such as wind speed and air temperature were not available. In order to provide a more detailed description of the atmospheric field, additional data from atmospheric model hindcasts were extracted for the selected period and location from the European Centre for Medium Range Weather Forecast archive. Measurements of the wavefield such as significant wave height and peak period were extracted from records of the water surface elevation gathered with a nearby directional waverider buoy; the instrument also recorded sea surface temperature. Wave data were archived every 600 seconds.

[9] The wind and wavefields are shown in Figures 2a and $2 \mathrm{~b}$. The selected period includes six tropical cyclones, whose wind speed $\left(U_{\text {wind }}\right)$ at the measured location was above $10 \mathrm{~m} / \mathrm{s}$ and maximum significant wave heights was greater than $3 \mathrm{~m}$. The wavefield is also characterized by rather long dominant waves with average peak period $T_{p}$ of about $10.5 \mathrm{~s}$ (Figure 2b), corresponding to a wavelength of $175 \mathrm{~m}$. Although such conditions are favorable for injecting a considerable amount of turbulence by the wave orbital motion (down to a depth of approximately half the wavelength), we stress that shear induced turbulence and wave breaking-induced turbulence are also produced during cyclones, contributing to ocean mixing.

[10] Due to the absence of salinity data, the mixed layer depth was estimated using the temperature profile only. Specifically, it was defined as the depth of the base of a subsurface layer, where the temperature has changed by a small amount from the reference value closest to the surface [Kara et al., 2003]. For the present study, this difference was fixed at $0.02{ }^{\circ} \mathrm{C}$ [cf. Thomson and Fine, 2003]. Owing to a limited number of measured points, the recorded profiles were refined by interpolated values to obtain a more accurate approximation of the mixed layer; depths smaller than $20 \mathrm{~m}$ could not be detected due to the lack of instruments in this zone, though. Note that the data interpolation was carried out on the assumption that the temperature gradients are linear. This feature was reported in a number of studies during the period from October to April (i.e., summer and early autumn in the Southern Hemisphere [Hallegraeff and Jeffrey, 1984; Sampey et al., 2004; Van Gastel et al., 2009]). Nonetheless, the estimation of the mixed layer depth has to be regarded qualitatively rather than quantitatively. In this respect, it is important to remark that the scope of the present study is the investigation of large changes in the mixed layer depth and not its careful evaluation.

[11] The presence of strong internal wave activity is responsible for oscillations of the water temperature with periods between 11 and $13 \mathrm{~h}$, which may induce a substantial deepening of the upper mixed layer [see, e.g., Van Gastel et al., 2009]. The internal waves may also be responsible for the generation of shocks (or hydraulic jumps) and relatively short frequency internal waves (or solitons) with periods of about $20 \mathrm{~min}$, which may induce additional mixing to the upper ocean [see, e.g., Holloway, 1987; Smyth and Holloway, 1988]. This effect appears in time series of water temperature in the form of a clear and regular oscillation with dominant period close to and lower than the one of the semidiurnal tide. As the investigation of this effect is outside the scope of the present study, however, the contribution of internal waves was removed by low-pass filtering the temperature data at the threshold period of $13 \mathrm{~h}$. Note that this filter removes the contribution of both the internal tide and 


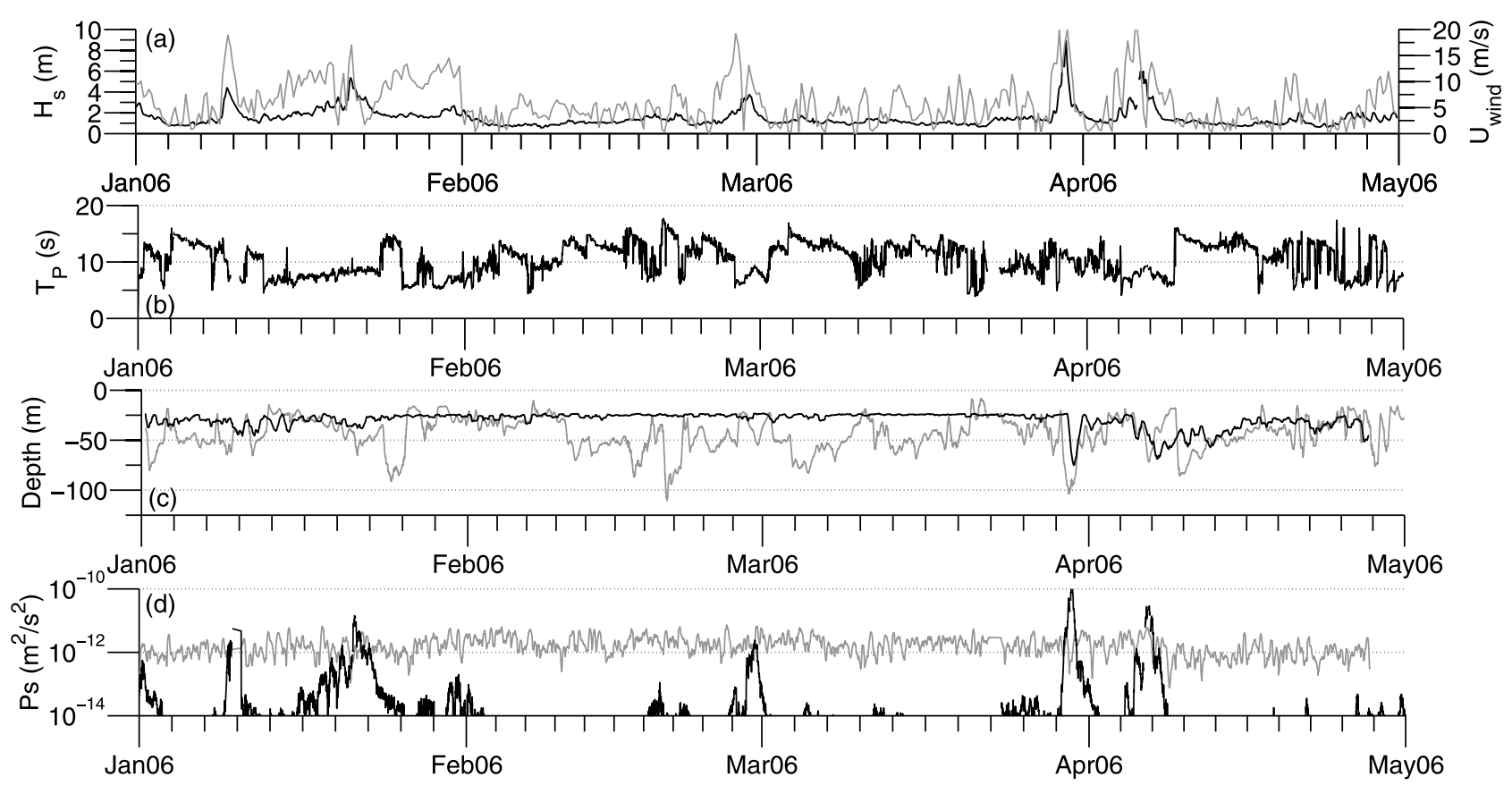

Figure 2. Ocean conditions: (a) significant wave height as a solid black line and wind speed as a solid grey line (wind speed was obtained from the atmospheric model run by the European Centre for Medium Range Weather Forecasts), (b) spectral peak period,(c) observed mixed layer depth as a solid black line and wave induced mixed layer depth as a solid grey line, and (d) wave turbulent kinetic energy production $(P w)$ as a solid black line and current turbulent kinetic energy production $(P s)$ as a solid grey line.

nonlinear internal waves originating from the degradation of the internal tide.

\section{Deepening of the Mixed Layer}

\subsection{Observations Based on Water Temperature Profiles}

[12] The effect of wave motion on the ocean mixing is strongly related to sea state conditions. The presence of generally long waves (average peak period of $10.5 \mathrm{~s}$ ), in this respect, forces the wave-induced mixed layer $\left(z_{c r}\right)$ to regularly oscillate between depths of 20 and $100 \mathrm{~m}$ (see grey line in Figure 2c). Despite the injection of turbulence to considerable depths, the Australian North-West Shelf is generally characterized by a stable stratification due to the intense solar heating. This results in a shallow mixed layer, which does not generally extend beyond a depth of 20-25 m. Note also that periods of strong stratification are normally characterized by rather low waves $\left(H_{s}<3 \mathrm{~m}\right)$ and thus wave-induced turbulence may not be sufficiently strong to produce any significant effect.

[13] During cyclones, nonetheless, a considerable enhancement of mixing through the water column is induced by the intensification of the wave activity. This results in a substantial deepening of the mixed layer, which is to some extent consistent with the wave-induced mixing $\left(z_{c r}\right)$. Because it takes some time for the turbulence to mix the upper ocean, there is a time lag between the peak of the wave-induced and the actual mixed layer depth (Figure 2c). Interestingly enough, this expansion occurs rapidly after the beginning of the storm. On average, the mixed layer deepens at a speed of about $0.7 \times 10^{-3} \mathrm{~m} / \mathrm{s}$, with a maximum of $1.5 \times 10^{-3} \mathrm{~m} / \mathrm{s}$ during the most severe cyclone at the end of March, 2006. Therefore, an expansion of the mixed layer of about $50 \mathrm{~m}$ would take 15-20 hours to happen. This time frame is considerably smaller than the one necessary to diffuse turbulence from the surface (see turbulent diffusion rates in Huang et al. [2011]) and hence it excludes any significant contribution from wave breaking. Furthermore, the effect of wind-driven Langmuir circulations, which may contribute greatly to the mixed layer depth under relatively mild wind conditions [Li et al., 1995], is generally weaker than the one induced by the wave orbital motion. Under the influence of a wind speed of approximately $15 \mathrm{~m} / \mathrm{s}$, for example, the subsurface layer subjected to Langmuir circulations is about $40 \%$ less deep than $z_{c r}$ [cf. Babanin et al., 2009].

\subsection{Turbulent Kinetic Energy Production}

[14] Generally, there is not a clear agreement between the measured mixed layer depth $\left(M_{l d}\right)$ and the wave-induced mixing layer depth $\left(z_{c r}\right)$ (see Figure 2c). A substantial deepening of $M_{l d}$ consistent with $z_{c r}$ occurred only in four out of six selected storms, so the role of wave-induced turbulence remains uncertain. Because the measurement station is subjected to a constant source of shear turbulence produced by the Leeuwin Current, which has an average speed of $0.1-0.15 \mathrm{~m} / \mathrm{s}$ and significantly increases through the water column during cyclones, it is likely that the current flow sometimes dominates the production of turbulent kinetic energy and hence restrains the contribution of wave-induced motion. This would imply that turbulence generated by nonbreaking waves may influence the mixed layer depth only if wave-induced turbulent kinetic energy production overpowers the contribution from the background shear current. 


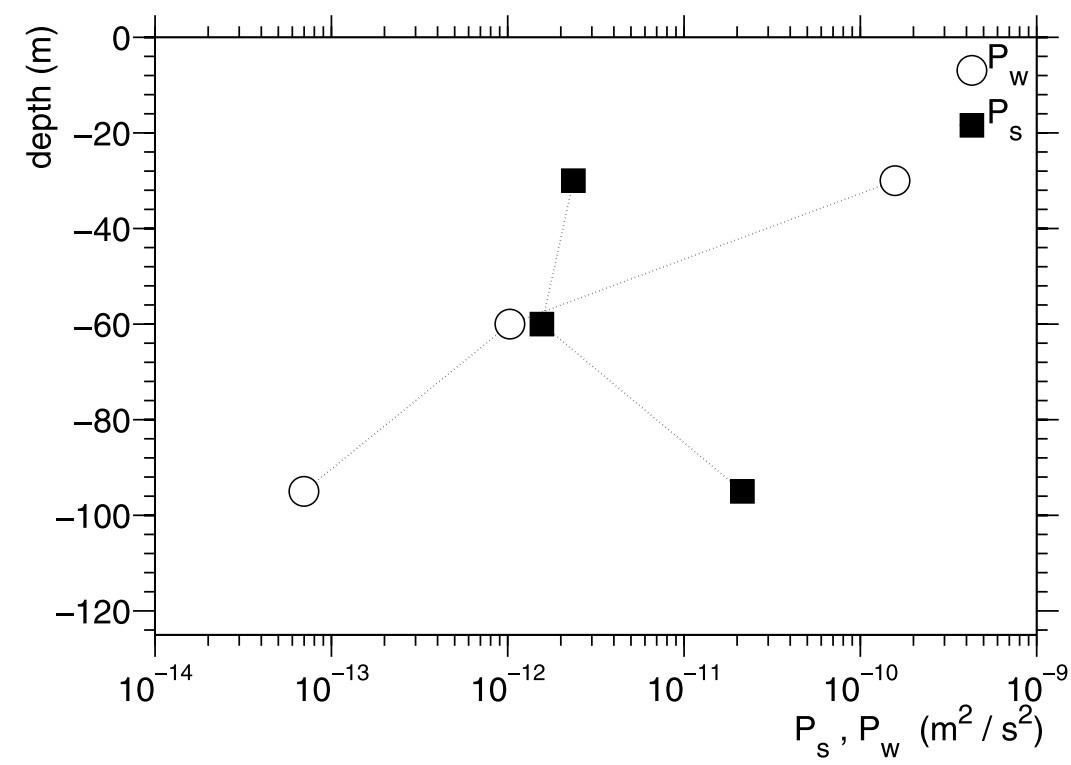

Figure 3. Turbulent kinetic energy production at the peak of the most intense storm (March 2006).

[15] To verify this conjecture, the turbulent kinetic energy production associated with the current field $(P S)$ and wave-induced motion $(P w)$ has been estimated. Following Pleskachevsky et al. [2011], Ps can be calculated as

$$
P s=v_{t} M_{c}^{2},
$$

where $v_{t}$ is the eddy viscosity and $M_{c}^{2}=\left(d u_{x} / d z\right)^{2}+\left(d u_{z} / d x\right)^{2}$ is the shear frequency (being $u_{x}$ and $u_{z}$ the flow velocity in the horizontal and vertical direction, respectively). It should be noted that there were no measurements of the vertical velocity $\left(u_{z}\right)$ available for this study. At tropical latitudes, however, the Leeuwin Current is characterized by a slow and steady vertical velocity field (on average, $u_{z} \approx 10^{-5} \mathrm{~m} / \mathrm{s}$ [see, e.g., Domingues, 2006]). Therefore, the assumption is made that the contribution of $u_{z}$ in (3) does not overpower the contribution of $u_{x}$. As a consequence, the current shear associated with the vertical component of the velocity field is neglected from the present analysis. Overall, the current shear was estimated over the three available intervals as defined by the position of the four instruments (see section 2).

[16] Evaluating the turbulent kinetic energy production from (3) we determined that it assumed relatively low values, oscillating between $P S=1 \times 10^{-12}$ and $4 \times 10^{-12} \mathrm{~m}^{2} / \mathrm{s}^{2}$ within a $95 \%$ confidence interval. However, whereas $P S$ remains generally constant through the water column, an increase in the production of current induced turbulent kinetic energy takes place near the seafloor (below depths of $60 \mathrm{~m}$ ) during tropical cyclones.

[17] The contribution of wave-induced motion to the turbulent kinetic energy can be calculated as

$$
P w=v_{t}\left(k_{\text {wave }}^{A M} \bar{M}_{\text {wave }}^{z}\right)^{2} .
$$

The coefficient $k_{\text {wave }}^{A M}$ refers to the amount of wave energy that is dissipated due to the turbulent fluctuations on the idealized orbital motion [Pleskachevsky et al., 2011]. Its value, $k_{\text {wave }}^{A M}=1.5 \times 10^{-4}$, was derived experimentally by measuring the loss of wave energy during the propagation of a gently sloping (i.e., non-breaking) monochromatic wave with frequency of $1.5 \mathrm{~Hz}$ [Babanin et al., 2009]. The shear frequency $\bar{M}_{\text {wave }}^{z}$ is calculated as a depth-integrated value of the shear frequency of linear waves:

$$
\bar{M}_{\text {wave }}(z)=\left(\frac{k \pi H_{s}}{T_{p}} \frac{\sin h[k(z+d)]}{\sin h(k d)}\right)
$$

with $T_{p}$ the peak wave period, $z$ the arbitrary depth at which the shear frequency is calculated and $d$ the water depth at the measurement stations (see Pleskachevsky et al. [2011] and Huang et al. [2011] for more details).

[18] In mild sea state conditions, the depth-integrated production of wave-induced turbulent kinetic energy is generally 3 orders of magnitude lower than the depth-integrated contribution of the shear current (for example, $P_{w} \approx 5 \times 10^{-15}$ between February and March, see Figure 2d). In these periods, no changes to the mixed layer depth were observed, even though the wave-induced motion extended to rather deep subsurface layers. Note that, under these circumstances, the stable stratification may have suppressed the weak waveinduced turbulence field (cf. the Monin-Obukhov effect in the atmosphere [Pahlow et al., 2001]). During cyclones, on the other hand, $P w$ increases rapidly. Generally, this results in a significant deepening of the mixed layer $M_{l d}$ in agreement with $z_{c r}$, when the depth-integrated $P w$ is equal to or greater than the depth-integrated PS (Figure 2d). Note that the wave motion tends to dominate the turbulent kinetic energy production until mid depth, while the current shear only prevails at deeper layers. In this respect, the shear current seems to only support an already deep mixed layer rather than initiate the mixing of a surface stratification. As an example, a hourly-averaged turbulent kinetic energy production at the peak of the most intense cyclone (March 2006) is presented in Figure 3 for three specific depths. 


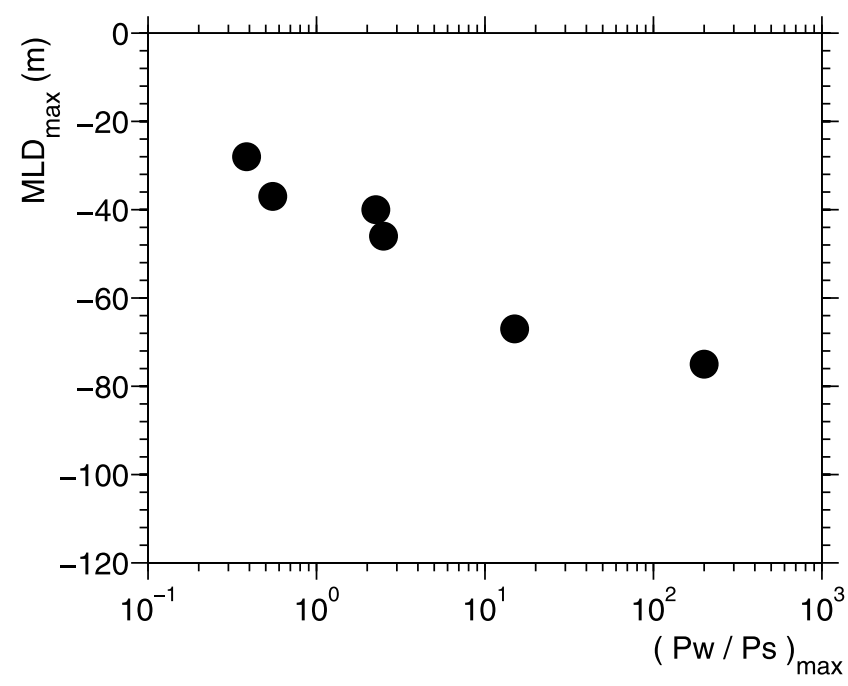

Figure 4. Maximum deepening of the mixed layer depth during tropical storms as the function of the maximum hourly-averaged ratio of wave-induced $(P w)$ to currentinduced $(P s)$ turbulent kinetic energy production during cyclones.

[19] The correlation between the mixed layer depth and the maximum hourly-averaged ratio of the wave-induced to current-induced turbulent kinetic energy production at the storm peaks is presented in Figure 4. It confirms that the mixed layer indeed remains shallow when the shear current is the dominant source of turbulence, i.e., $(P w / P s)_{\max }<1$. However, there is a robust and consistent tendency for the mixed layer to deepen with the increase of the ratio $(P w / P s)_{\max }$ as the wave-induced turbulent kinetic energy production gradually overpowers the contribution from the ocean current.

\section{A Case Study: The Evolution of the Mixed Layer During the Most Severe Cyclone}

[20] It is instructive to present the evolution of the water temperature profile for the most severe storm. Figure 5 displays the time evolution of significant wave height (Figure 5a), mixed layer depth (Figure 5b), isotherms (Figure $5 \mathrm{c}$ ), and vertical profiles of water temperature at intervals of 10 hours (Figures $5 \mathrm{~d}-5 \mathrm{~h}$ ).

[21] At an early stage of the storm (see Figures $5 \mathrm{~b}$ and 5d), the initial growth in wave activity coincides with a rapid deepening of $z_{c r}$. The mixed layer depth, however, does not seem to respond promptly to wave-induced turbulence and the ocean still remains strongly stratified for a further period of about 10 hours. At this stage (Figures $5 \mathrm{~b}$ and $5 \mathrm{e}$ ), the production of wave-induced turbulent kinetic energy shows a significant enhancement of almost four orders of magnitude, overpowering the contribution of the background current. As a result of an enhanced mixing of the upper ocean, the warm water at the surface is rapidly forced to mix, bringing the temperature to uniformity through the water column (see Figure $5 \mathrm{~b}$ and especially the isotherms in Figure $5 \mathrm{c}$ ). The transition from a stratified to a uniform water temperature, here corresponding to a mixed layer depth $M_{l d} \approx 80 \mathrm{~m}$, is achieved within a period of about 20 hours, which is much shorter than the timescale required by, e.g., Langmuir circulations to induce a similar effect [cf. Li et al., 1995; Babanin et al., 2009].

[22] The mixed layer $M_{l d}$ remains deep as long as $P w$ overpowers the current-induced turbulent kinetic energy (Figures $5 \mathrm{e}-5 \mathrm{~g}$ ). This condition, nonetheless, rapidly decays (within 10 hours) after the peak of the cyclone, despite the
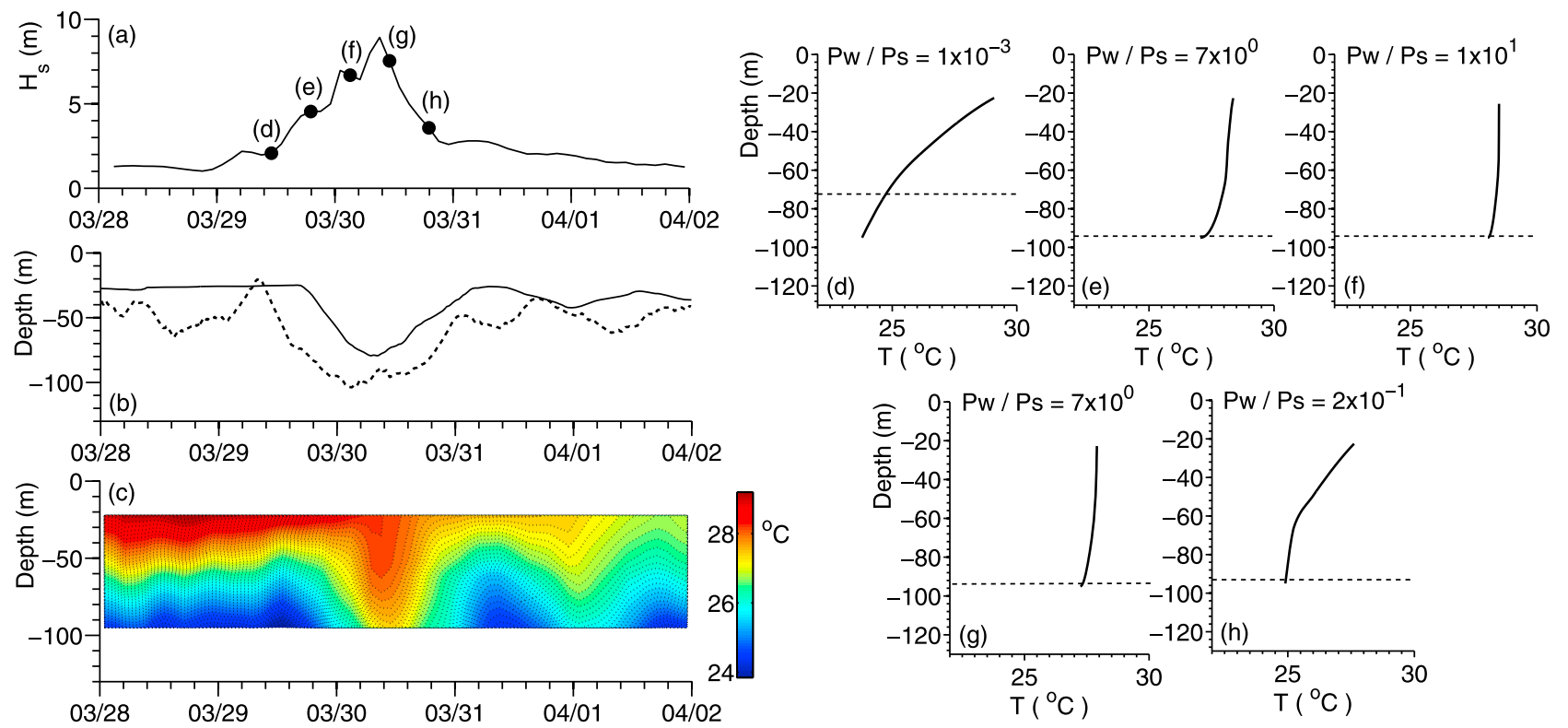

Figure 5. Temporal evolution of the water temperature profile during the most extreme wave storm (March 2006): (a) evolution of significant wave height, (b) evolution of the wave-induced ( $z_{c r}$, dashed line) and observed ( $M_{l d}$, solid line) mixed layer depth, (c) isotherms, and (d-h) vertical profiles of water temperature taken at time intervals of 10 hours (solid line) and wave-induced mixed layer depth $z_{c r}$ (dashed line). 


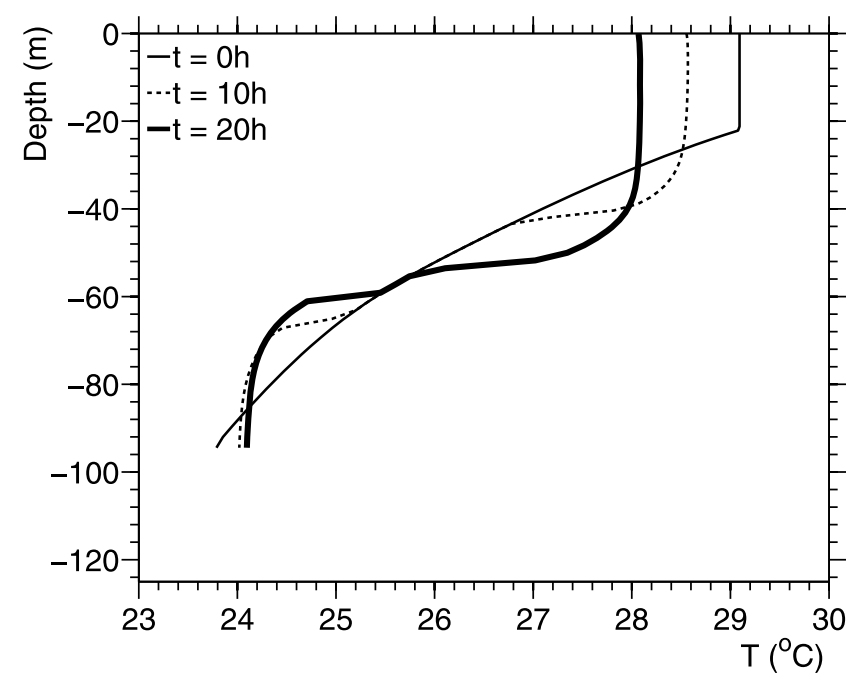

Figure 6. Temperature profile as simulated by the Global Ocean Turbulence Model (GOTM). The initial temperature profile is taken at the beginning of the storm (see Figure $5 \mathrm{~d}$ ). The hourly-averaged current profile and atmospheric forcing at approximately the peak of the storm (point $\mathrm{f}$ in Figure 5a) are provided as input. Note that the profiles at $\mathrm{t}=10 \mathrm{~h}$ and $20 \mathrm{~h}$ correspond to the field data in Figures 5e and 5f, respectively.

still deep injection of wave-induced motion. When $P_{s}>P_{w}$, the initially stratified condition is reestablished (Figure $5 \mathrm{~h}$ ). It is not yet clear why stratification is restored so quickly during the decay of the storm. However we cannot exclude the possibility that the horizontal advection that takes place after the cyclone has passed may constrain an already weakening wave-induced turbulence [see, e.g., Cushman-Roisin, 1981]. Although there are some quantitative differences between the values of $M_{l d}$ and $z_{c r}$, predictions based on the principle of wave-induced turbulence describe the dynamics of the mixed layer depth consistently. Field measurements, however, tend to indicate that the deepening of the mixed layer develops more rapidly than theory would predict (see the time evolution of $M_{l d}$ and $z_{c r}$ in Figure $5 \mathrm{~b}$ ).

[23] Although the empirical analysis seems to point at a significant contribution of wave-induced turbulence in the mixing of the upper ocean, we stress that the data are contaminated by many other processes such as convection, wave breaking, currents and atmospheric forcing. While wave-breaking can be excluded as its contribution toward ocean mixing is mainly limited to a near surface layer as thick as the wave height [see Terray et al., 1996], we cannot neglect $a$ priori the effect of atmospheric forcing and the ocean currents. In order to dispel any doubts on their significance, simulations have been carried out with the General Ocean Turbulence Model (GOTM) [Burchard et al., 1999; Umlauf and Burchard, 2005]. GOTM is a one-dimensional ocean mixing model, which solves transport equations for heat, salinity and momentum based on a number of different turbulent mixing schemes; the k-epsilon turbulence model in Rodi [1987] has been used for the present study. Note that no wave physics was allowed in the simulations.

[24] The 10-meter wind speed, humidity, air temperature, cloud cover, sea level pressure and an hourly-averaged current profile were all prescribed at the approximate peak of the storm (see point $\mathrm{f}$ in Figure 5a). The stratified temperature profile at the beginning of the storm (Figure $5 \mathrm{~d}$ ) was provided as initial condition. The sea surface temperature was observed to be consistent with the water temperature at $22.5 \mathrm{~m}$ and hence a uniform temperature profile was assumed within this near-surface layer (i.e., up to a depth of $22.5 \mathrm{~m}$ ). Furthermore, the bulk parameterization in Fairall et al. [1996] was used to determine the surface fluxes. Note that because no salinity data were available, the model was run without solving the salt transport equations. A randomly chosen stable salinity profile was applied in testing and we found that its effect on the results was negligible. The model was run to simulate the effect of ocean turbulence over a realtime period of 20 hours. The initial profile as well as the profiles after 10 and 20 hours is presented in Figure 6.

[25] The simulation indicates that the overall effect of current and atmospheric forcing results in the near surface mixed layer reaching down to a depth of approximately $30 \mathrm{~m}$ after the first 10 hours, and about $40 \mathrm{~m}$ after 20 hours. Note also that water temperature tends to become more uniform near the seafloor, yet a strong stratification persists at intermediate depth (between depths of 40 and $70 \mathrm{~m}$ ). In this respect, it is important to mention that the deepening of the surface mixed layer is mainly related to the atmospheric forcing. Simulations with current only, in fact, do not show any significant variation of the upper mixed layer, but only mixing at the sea floor. This result, however, is not unexpected as the background current and the associated shear turbulence are observed to increase substantially at the base of the water column. Considering that measurements already show a uniform temperature profile through most of the water column after about 10 hours from the beginning of the storm (e.g., Figure 5e), the simulations suggest that an additional source of turbulence is necessary to reproduce the observed mixed layer, indirectly supporting the empirical conclusion on the significance of wave-induced turbulence on ocean mixing.

\section{Conclusions}

[26] Measurements of water temperature profiles during tropical storms in the Eastern Indian Ocean have been analyzed to investigate the effect of turbulence induced by wave orbital motion on the ocean mixed layer. The measurement station is located on the Australian North-West Shelf approximately $135 \mathrm{~km}$ offshore. An array of 5 current meters and temperature sensors distributed over the water column was deployed at the site. The region is affected by a background current of average speed of $0.1-0.15 \mathrm{~m} / \mathrm{s}$ and internal waves of period ranging between 11 and $13 \mathrm{~h}$, which can affect the ocean mixing. The effect of the latter, however, has been filtered from the data.

[27] Despite the influence of waves and current, the mixed layer is generally shallow and only deepens significantly as a consequence of the intensification of wave activity during tropical cyclones. Note that the deepening of the mixed layer has to be considered qualitatively rather than quantitatively due to the scattered distribution of the instruments and the interpolation of the water temperature profile. Nonetheless, observations indicate that the deepening of the mixed layer is initiated when wave-induced turbulence is sufficiently strong to overpower the contribution of the background shear current. This result is substantiated by a robust and consistent 
expansion of the mixed layer with the increase of the ratio of wave-induced to current-induced turbulent kinetic energy production. When the shear current remains the principal source of turbulence, though, no changes in the mixed layer depth were recorded.

[28] Under the effect of tropical cyclones, the mixed layer expands at an average speed of the order of $10^{-3} \mathrm{~m} / \mathrm{s}$. This implies that a deepening of $50 \mathrm{~m}$ would occur within timescales of about 10 hours (i.e., 3600 dominant wave periods, on average). While the quick deepening of the mixed layer excludes effects of wave breaking and Langmuir circulation, which may require several days to induce a similar variation, it also seems to substantiate the role of turbulence induced by wave orbital motion in mixing the upper ocean. However, we stress that the observations include the effects of many processes other than waves. In order to dispel any doubts on the significance of the effect of the background current and atmospheric forcing on the ocean mixing, numerical simulations without wave physics, were carried out by means of the Global Ocean Turbulence Model (GOTM). Results seem to support the empirical conclusion on the key role played by wave-induced turbulence, indicating that currents and atmospheric forcing are not on their own able to account for the mixing through most of the water column.

[29] Acknowledgments. Financial support of the Australian Research Council and Woodside Energy Ltd through the grant LP0883888 is acknowledged. Australian Research Council grant DP1093517 is also acknowledged. Field observations from North Rankin A Gas Platform were kindly provided by Woodside Energy Ltd (who remains the sole owner of any proprietary rights in the field observations). L.L. has been supported by the E.U. project SEAMOCS (contract MRTNPCTP2005P019374).

\section{References}

Babanin, A. V. (2006), On a wave-induced turbulence and a wave-mixed upper ocean layer, Geophys. Res. Lett., 33, L20605, doi:10.1029/ 2006GL027308.

Babanin, A. V. (2011), Breaking and Dissipation of Ocean Surface Waves, Cambridge Univ. Press, Cambridge, U. K.

Babanin, A. V., and B. K. Haus (2009), On the existence of water turbulence induced by nonbreaking surface waves, J. Phys. Oceanogr., 39, 2675-2679, doi:10.1175/2009JP04202.1.

Babanin, A. V., A. Ganopolski, and W. R. C. Phillips (2009), Wave-induced upper-ocean mixing in a climate modelling of intermediate complexity, Ocean Modell., 29, 189-197.

Baumert, H. Z., J. Simpson, and J. Sündermann (Eds.) (2005), Marine Turbulence-Theory, Observations, and Models, 652 pp., Cambridge Univ. Press, Cambridge, U. K.

Burchard, H., K. Bolding, and M. R. Villarreal (1999), GOTM, a General Ocean Turbulence Model: Theory, Implementation and Test Cases, Space Appl. Inst., Ispra, Italy.

Cavaleri, L., and S. Zecchetto (1987), Reynolds stresses under wind waves, J. Geophys. Res., C92, 3894-3904.

Chalikov, D. V., and M. Y. Belevich (1993), One-dimensional theory of the wave boundary layer, Boundary Layer Meteorol, 63(1), 65-96.

Craig, P., and M. Banner (1994), Modeling wave-enhanced turbulence in the ocean surface layer, J. Phys. Oceanogr., 24(12), 2546-2559.

Cushman-Roisin, B. (1981), Effects of horizontal advection on upper ocean mixing: A case of frontogenesis, J. Phys. Oceanogr., 11, 1345-1356.

Dai, D., F. Qiao, W. Sulisz, L. Han, and A. Babanin (2010), An experiment on the nonbreaking surface-wave-induced vertical mixing, J. Phys. Oceanogr., 40(9), 2180-2188.

Domingues, C. M. (2006), Kinematics and heat budget of the Leeuwin Current, $\mathrm{PhD}$ thesis, Flinders University of South Australia, Adelaide, S. Aust., Australia.

Fairall, C. W., E. F. Bradley, D. P. Rogers, J. B. Edson, and G. S. Youngs (1996), Bulk parameterization of air-sea fluxes for tropical oceanglobal atmosphere coupled-ocean atmosphere response, J. Geophys. Res., 101(C2), 3747-3764.

Gemmrich, J. R., and D. M. Farmer (2004), Near-surface turbulence in the presence of breaking waves, J. Phys. Oceanogr., 34, 1067-1086.
Hallegraeff, G. M., and S. W. Jeffrey (1984), Tropical phytoplankton species and pigments of continental shelf waters of north and north-west Australia, Mar. Ecol. Prog. Ser., 20(1), 59-74.

Holloway, P. E. (1987), Internal hydraulic jumps and solitons at a shelf break region on the Australian North West Shelf, J. Geophys. Res, 92(C5), 5405-5416.

Holloway, P. E. (1994), Observations of internal tide propagation on the Australia North West shelf, J. Phys. Oceanogr., 24, 1706-1716.

Huang, C. J., F. Qiao, Z. Song, and T. Ezer (2011), Improving simulations of the upper ocean by inclusion of surface waves in the Mellor-Yamada turbulence scheme, J. Geophys. Res., 116, C01007, doi:10.1029/ 2010JC006320.

Kara, A. B., P. A. Rochford, and H. E. Hurlburt (2003), Mixed layer depth variability over the global ocean, J. Geophys. Res., 108(C3), 3079, doi:10.1029/2000JC000736.

Kukulka, T., A. J. Plueddemann, J. H. Trowbridge, and P. P. Sullivan (2010), Rapid mixed layer deepening by the combination of Langmuir and shear instabilities: A case study, J. Phys. Oceanogr., 40, 2381-2400.

Li, M., and C. Garrett (1997), Mixed layer deepening due to Langmuir circulation, J. Phys. Oceanogr., 27, 121-132.

Li, M., K. Zahariev, and C. Garrett (1995), Role of Langmuir circulation in the deepening of the ocean surface mixed layer, Science, 270(5244), 1955-1957.

Mellor, G. L., and P. A. Durbin (1975), The structure and dynamics of the ocean surface mixed layer, J. Phys. Oceanogr., 5, 718-728.

Pahlow, M., M. Parlange, and F. Porté-Agel (2001), On Monin-Obukhov similarity in the stable atmospheric boundary layer, Boundary Layer Meteorol., 99(2), 225-248.

Phillips, W. R. C. (2001), On an instability to Langmuir circulation and the role of Prandtl and Richardson numbers, J. Fluid Mech., 442, 335-358.

Pleskachevsky, A., G. Gayer, J. Hosrstman, and W. Rosenthal (2005), Synergy of satellite remote sensing and numerical modeling for monitoring of suspended particulate matter, Ocean Dyn., 55, 2-9.

Pleskachevsky, A., M. Dobrynin, A. V. Babanin, H. Günther, and E. Stanev (2011), Turbulent mixing due to surface waves indicated by remote sensing of suspended particulate matter and its implementation into coupled modeling of waves, turbulence, and circulation, J. Phys. Oceanogr., 41, 708-724.

Qiao, F., Y. Yeli, Y. Yang, Q. Zheng, C. Xia, and J. Ma (2004), Waveinduced mixing in the upper ocean: Distribution and application to a global ocean circulation model, Geophys. Res. Lett., 31, L11303, doi:10.1029/2004GL019824.

Qiao, F., Y. Yang, C. Xia, and Y. Yeli (2008), The role of surface waves in the ocean mixed layer, Acta Oceanol. Sin., 27, 30-37.

Rapp, R. J., and W. K. Melville (1990), Laboratory measurements of deep water breaking waves, Philos. Trans. R. Soc. London, Ser. A, 331, $735-780$.

Rodi, W. (1987), Examples of calculation methods for flow and mixing in stratified fluids, J. Geophys. Res., 92(C5), 5305-5328.

Sampey, A., M. G. Meekan, J. H. Carleton, A. D. McKinnon, and M. McCormick (2004), Temporal patterns in distributions of tropical fish larvae on the north west shelf of Australia, Mar. Freshwater Res., 55(5), 473-487.

Smyth, N. F., and P. E. Holloway (1988), Hydraulic jump and undular bore formation on a shelf break, J. Phys. Oceanogr, 18(7), 947-962.

Sullivan, P. P., and J. C. McWilliams (2010), Dynamics of winds and currents coupled to surface waves, Annu. Rev. Fluid Mech., 42, 19-42.

Terray, E. A., M. A. Donelan, Y. C. Agrawal, W. M. Drennan, K. K Kahma, A. J. Williams III, P. A. Hwang, and S. A. Kitaigorodskii (1996), Estimates of kinetic energy dissipation under breaking waves, J. Phys. Oceanogr., 26, 792-807.

Thais, L., and J. Magnaudet (1996), Turbulent structure beneath surface gravity waves sheared by the wind, J. Fluid Mech., 328, 313-344.

Thomson, R. E., and I. V. Fine (2003), Estimating mixed layer depth from oceanic profile data, J. Phys. Oceanogr., 20, 319-329.

Toffoli, A., A. V. Babanin, M. Onorato, and T. Waseda (2010), Maximum steepness of oceanic waves: Field and laboratory experiments, Geophys. Res. Lett., 37, L05603, doi:10.1029/2009GL041771.

Umlauf, L., and H. Burchard (2005), Second-order turbulence closure models for geophysical boundary layers. A review of recent work, Cont. Shelf Res., 25(7-8), 795-827.

Van Gastel, P., G. N. Ivey, M. J. Meuleners, J. P. Antenucci, and O. Fringer (2009), The variability of the large-amplitude internal wave field on the Australian North West Shelf, Cont. Shelf Res., 29, 1373-1383.

Yefimov, V. V., and G. N. Khristoforov (1971), Spectra and statistical relations between the velocity fluctuations in the upper layer of the sea and surface waves, Izv. Atmos. Ocean. Phys., 7, 1290-1310.

Young, I. R. (2006), Directional spectra of hurricane wind waves, J. Geophys. Res., 111, C08020, doi:10.1029/2006JC003540. 